\title{
Clinical Features and Treatment Outcomes of Acute Multiple Thoracic and Lumbar Spinal Fractures : A Comparison of Continuous and Noncontinuous Fractures
}

\author{
Yongjae Cho, Young Goo Kim \\ Department of Neurosurgery, Ewha Womans University College of Medicine, Seoul, Korea
}

Objective : The treatment of multiple thoracolumbar spine fractures according to fracture continuity has rarely been reported. Herein we evaluate the clinical features and outcomes of multiple thoracolumbar fractures depending on continuous or noncontinuous status.

Methods : From January 2010 to January 2016, 48 patients with acute thoracic and lumbar multiple fractures who underwent posterior fusion surgery were evaluated. Patients were divided into two groups (group A : continuous; group B : noncontinuous). We investigated the causes of the injuries, the locations of the injuries, the range of fusion levels, and the functional outcomes based on the patients' general characteristics.

Results : A total of 48 patients were enrolled (group A : 25 patients; group B : 23 patients). Both groups had similar pre-surgical clinical and radiologic features. The fusion level included three segments (group $A: 4 ;$ group $B: 5$ ) or four segments (group $A$ : 19; group B : 5). Group B required more instrumented segments than did group A. Group A scored 23.5 and group B scored 33.4 on the Korean Oswestry Disability Index (KODI) at the time of last follow-up. In both groups, longer fusion was associated with worse KODI score.

Conclusion : In this study, due to the assumption of similar initial clinical and radiologic features in both group, the mechanism of multiple fractures is presumed to be the same between continuous and noncontinuous fractures. The noncontinuous fracture group had worse KODI scores in long-term follow-up, thought to be due to long fusion level. Therefore, we recommend minimizing the number of segments that are fused in multiple thoracolumbar and lumbar fractures when decompression is not necessary.

Key Words : Spinal fractures · Decompression · Fractures, Multiple.

\section{INTRODUCTION}

Continuous multiple vertebral fracture is a fracture type involving more than two consecutive fractured vertebral seg- ments, while non-continuous multiple vertebral fracture composed of fractures separated by normal vertebral segments ${ }^{23}$. In the thoracic and lumbar spine, most multiple vertebral fractures occur due to high-energy trauma resulting in

\footnotetext{
- Received : April 11, 2019 •Revised : June 6, $2019 \bullet$ Accepted : July 2, 2019

- Address for reprints : Yongjae Cho

Department of Neurosurgery, Ewha Womans University College of Medicine, 1071 Anyangcheon-ro, Yangcheon-gu, Seoul 07985, Korea

Tel : +82-2-2650-2685, Fax : +82-2-2650-2651, E-mail : yongcho@ewha.ac.kr, ORCID : https://orcid.org/0000-0002-4498-1184
}

This is an Open Access article distributed under the terms of the Creative Commons Attribution Non-Commercial License (http://creativecommons.org/licenses/by-nc/4.0) which permits unrestricted non-commercial use, distribution, and reproduction in any medium, provided the original work is properly cited. 
unstable fractures and necessitating surgical fixation to obtain stability of the compromised segment ${ }^{23)}$. However, it is assumed that multiple thoracic and lumbar spine fractures according to fracture continuity differ from each other depending on the cause of injury, fracture morphology, level of fracture, and prognosis ${ }^{9)}$. Most acute multiple unstable thoracolumbar fractures patients without osteoporosis undergo surgical treatment in order to maintain stability of the vertebral column, but their surgical option is subjected to long segment fixation, often resulting in postoperative complications such as limitations of spinal motion, failure of instrumental devices. Noncontinuous thoracic and lumbar spine fractures are rare and the literature reporting this subject is more scarce compared to that reporting continuous fractures. As usual, in the case of multiple thoracolumbar fractures, the surgeon decides upon the fixation level and extent depending on the patient's neurologic status and spinal instability corresponding to the fractures. The optimal approach to the management of these patients has yet to be recognized.

As such, we aimed to retrospectively analyze patients with multiple thoracic and lumbar spine fractures with regard to fracture continuity. The patient demographic findings, cause of injury, radiologic findings, fracture classification, surgical findings, and prognosis were included. The main purpose of this study was to evaluate the clinical features of multiple thoracolumbar spinal fractures and compare the surgical effects according to fracture continuity.

\section{MATERIALS AND METHODS}

\section{Patients}

This study was approved by Ewha Womans Mokdong Hospital Bioethics Commitee (IRB no. 2018-05-16-0012). We retrospectively analyzed 48 patients among 85 patients who were diagnosed with acute multiple thoracic and lumbar fractures and who underwent surgery between January 2010 and January 2016 in our hospital. Eligible patients were those with acute multiple unstable thoracic and lumbar fractures unrelated to osteoporosis who were surgically treated and observed for more than 2 years. The osteoporotic fractures patients were excluded and the criteria for osteoporotic fractures were as follows 1) older than 50 years of age, 2) having a history of osteoporotic compression fracture, and 3) less than -2.5 score in bone mineral density.

Study participants were classified into two groups based on fracture continuity. The patients with continuous fractures was defined as group A (continuous type; 25 patients) and the patients with fractures separated by normal vertebral segments were defined as group B (non-continuous type; 23 patients).

\section{Methods}

Demographic findings including sex, age, cause of injury were examined. Radiologically, the locations of the injured vertebrae and the number of injured segments as well as the type of injury were investigated. The main fracture of the injury was defined as a fracture, distraction, or dislocation that: 1) appeared to be most unstable on the plain radiographs, computed tomography (CT), and magnetic resonance imaging (MRI) scans or 2) was associated with a neurological deficit. The minor fractures of injury were relatively more stable than the major fracture by radiographic criteria and were not related or were less-related with neurological status. For the type of injury, McAfee's classification was applied (e.g., wedge compression fracture, stable burst fracture, unstable burst fracture, Chance fracture, flexion distraction injury, Translation injury $)^{17)}$. According to McAfee's classification, the difference between stable burst fracture and unstable burst fracture was the presence of injury of vertebral posterior column ${ }^{17)}$.

The ranges of instrumentation, neurologic status, functional outcome, pain, and complications were investigated. Neurologic status was evaluated by using the American Spinal Injury Association (ASIA) scale. A visual analogue scale (VAS; 10 points) and the Korean Oswestry Disability Index (KODI) were used for determining functional outcome, which consisted of 10 sections such as pain intensity, personal care (i.e., washing, dressing), lifting, walking, sitting, standing, sleeping, social life, and traveling and ranged in possible score from 0 (no pain, healthy) to 5 (most severe pain) points ${ }^{11,12)}$. KODI was measured 1 month after surgery for the first time and then at 6-month intervals.

Continuous fractures were fixed to one or two segments below the unstable fracture. In noncontinuous fracture patients, if one of the upper or lower fractures was unstable and contributed to a neurological deficit while the others were stable, the most compromising fracture was fixed and the others were treated conservatively. When all fractures were consid- 
ered to contribute to neurologic deficit(s) and instability, all injured segments were instrumented.

The clinical results of the two groups were compared and analyzed. The analysis was conducted via the Statistical Package for the Social Sciences version 21.0 (SPSS) software program (IBM Corp., Armonk, NY, USA) using an independent samples t-test and bivariate correlation analysis, chi-squared test, and one-way analysis of variance. Statistical significance was considered to be when the $p$-value was less than 0.05 .

\section{RESULTS}

Study participant ages ranged from 18 to 50 years (mean, $35.4 \pm 11.3$ years) (Table 1$)$. The average age of group A (continuous fractures) was 31.4 years and the male to female ratio was 2.57 : 1 (18 males and seven females). In group A, there were 14 cases of motor vehicle accident, seven cases of falling from a large height, two cases of direct injury due to being hit by an object, and four cases resulting from other causes. Most cases in this group were the result of a high-energy injury such as a motor vehicle accident or a fall from a large height (23 cases;
$92 \%)$, while two cases (8\%) involved lower-energy injuries. The main fractures in group A included 16 cases at the thoracolumbar junction and four cases and five cases of above and below the thoracolumbar junction (T10-L2), respectively. Most of the multiple fractures in the thoracic and lumbar vertebrae were more frequently concentrated in the thoracolumbar area in both groups, regardless of fracture continuity (31/48 cases; $62.5 \%)$.

In group B (noncontinuous fractures), the mean age of the included patients was 36.3 years. Sixteen cases were present in males and seven in females. In group B, 14 cases were due to motor vehicle accidents, six were from falling from a large height, and three were from other injuries. Fractures resulting from a high-energy impact accounted for $86.9 \%$ of all cases (20 cases). The number of high-energy-related injuries in group $B$ was smaller than that in group A. Furthermore, those in group A were relatively younger as compared with in group B (31.4 vs. 36.3 years). In assessing whether there was a statistically significant difference in age and high-energy-related injury between the two groups, a Student's t-test revealed $p$-values of 0.115 and 0.128 , respectively. Thus, there was no statistical difference noted in age or cause of high-energy injury between the groups

Table 1. Demographics, location, and causes of multiple thoracolumbar vertebral fractures

\begin{tabular}{|c|c|c|c|}
\hline & Group A (contiguous type) & Group B (noncontiguous type) & $p$-value \\
\hline Case & 25 & 23 & \\
\hline $\operatorname{Sex}(M: F)$ & $18: 7$ & $16: 7$ & \\
\hline Mean age (years) & $31.4 \pm 11.3$ & $36.3 \pm 15.4$ & 0.115 \\
\hline Causes of injury & & & 0.128 \\
\hline Traffic accident & 14 & 14 & \\
\hline Pedestrian & 9 & 7 & \\
\hline Driver or passenger & 5 & 7 & \\
\hline Fall down & 7 & 6 & \\
\hline Above 2 story height & 5 & 4 & \\
\hline Below 2 story height & 2 & 2 & \\
\hline Others & 4 & 3 & \\
\hline Location of main fracture* & & & 0.152 \\
\hline Above T-L junction & 4 & 3 & \\
\hline T-L junction (T10-L2) & 16 & 15 & \\
\hline Below T-L junction & 5 & 5 & \\
\hline \multicolumn{4}{|l|}{ Initial neurologic status (ASIA) } \\
\hline$A: B: C: D: E$ & $7: 8: 5: 5: 0$ & $4: 5: 6: 8: 0$ & 0.085 \\
\hline
\end{tabular}

*Location of main fracture was shown Tables 4 and 5 in detail. M : male, F : female, T-L : thoracolumbar, ASIA : American Spinal Injury Association 
(Table 1).

In this study, there was no ASIA grade E for initial neurologic status in either group. Group A consisted of seven patients with ASIA grade $A$, eight with grade $B$, five with grade $\mathrm{C}$, and five with grade $\mathrm{D}$. On the other hand, group B included four with ASIA grade A, five with grade B, six with grade $\mathrm{C}$, and eight with grade D. Group A contained more neurologically compromised patients than did group $\mathrm{B}$, although there was no statistical difference $(p=0.085)$.

The number of multiple fractured vertebral segments was 15 cases with two fractures $(60.0 \%)$, eight cases with three fractures (32.0\%), and two cases with four fractures $(8.0 \%)$ in group A and 17 cases with two fractures (73.9\%), five cases with three fractures $(21.7 \%)$, and one case with four fractures $(4.3 \%)$ in group B. Base on this, there was no statistically significant difference in the number of fractures between the two groups (Table 2). Separately, the kyphotic angle and lumbar lordosis were $27.4^{\circ} \pm 14.9^{\circ}$ and $22.4^{\circ} \pm 12.1^{\circ}$ in group $\mathrm{A}$ and $25.5^{\circ} \pm 13.0^{\circ}$ and $23.5^{\circ} \pm 15.7^{\circ}$ in group $B$, with no statistically significant difference $(p=0.254$ and $p=0.325)$.
According to McAfee's classification, various fracture morphologies were observed regarding the combination of the main fracture and minor fractures, as follows : unstable burstcompression, distraction-compression, chance fracture-compression, translation-compression, unstable burst-unstable burst, unstable burst-distraction, and translation-unstable burst (Table 2). The most common types of major fractures were burst fractures in both groups (30/48; 62.5\%). The incidence of burst fracture was 64.0\% (16/25) for group A and $60.1 \%(14 / 25)$ for group B, followed by distraction injury in eight cases (16.7\%), translation in eight (16.7\%), and chance fracture in three (6.3\%). Group B had no unstable burst-distraction or unstable burst-translation type fractures.

The minor fractures were predominantly compression fractures in 18 patients (37.5\%, nine in group A, seven in group B). There was no difference in prevalence between the two groups according to the type of fracture $(p=0.157)$.

The extent of fixation performed during operation in group A was four cases involving three segments, 19 cases involving four segments, one case involving five segments, and one case

Table 2. Radiologic features of multiple thoracolumbar vertebral fractures

\begin{tabular}{|c|c|c|c|}
\hline & Group A (contiguous type) & Group B (noncontiguous type) & $p$-value \\
\hline \multicolumn{4}{|l|}{ Numbers of fractures } \\
\hline 2 segments & 15 & 17 & \\
\hline 3 segments & 8 & 5 & \\
\hline 4 segments & 2 & 1 & \\
\hline \multicolumn{4}{|c|}{ Numbers of instrumented vertebral segment } \\
\hline 3 segments & 4 & 5 & \\
\hline 4 segments & 19 & 5 & \\
\hline 5 segments & 1 & 10 & \\
\hline 6 segments & 1 & 3 & \\
\hline Kyphotic angle ( ${ }^{\circ}, \mathrm{T} 10-\mathrm{L} 2$, mean) & $27.4 \pm 14.9$ & $25.5 \pm 13.0$ & 0.254 \\
\hline Lordosis ( ${ }^{\circ}, T 12-S 1$, mean) & $22.4 \pm 12.1$ & $23.5 \pm 15.7$ & 0.325 \\
\hline Morphology of fracture* & & & 0.157 \\
\hline Unstable burst-stable burst & 7 & 8 & \\
\hline Distraction+compression & 5 & 3 & \\
\hline Chance+compression & 1 & 2 & \\
\hline Translation+compression & 3 & 4 & \\
\hline Unstable burst+unstable burst & 7 & 6 & \\
\hline Unstable burst+distraction & 1 & 0 & \\
\hline Unstable burst+translation & 1 & 0 & \\
\hline
\end{tabular}

${ }^{*}$ Combination of multiple fracture (main fracture+minor fracture) 
involving six segments. In group B, three segments were fixed in five cases, four segments were fixed in five cases, five segments were fixed in 10 cases, and six segments were fixed in three cases. Of note, the number of instrumented vertebral segments in group B (noncontinuous fractures) was higher than that in group A (continuous fractures). There were four cases in which iliac screws were inserted for fixation (one in group A and three in group B).

The preoperative VAS score was 8.4 points in group A and 7.5 points in $B$ group, while the VAS score at the time of last follow-up was 3.4 points in group A and 2.8 points in group B. There was no statistical difference $(p=0.386$ ) (Table 3 ).

Clinical evaluation using the KODI showed an average of 23.5 points in group $\mathrm{A}$ and 33.4 points in group $\mathrm{B}$ at the time of last follow-up. KODI score improved more so in group A from 45.3 to 23.5 versus from 42.8 to 33.4 in group B. Upon comparing the mean KODI between the two groups, group A showed better clinical outcomes than did group B, which were statistically significant ( $p=0.018$ ).

The higher the number of fractured segments in each group, the less clinical result was as presented via KODI score.
This finding was statistically significant $(p=0.035)$ according to Pearson's correlation.

Neurologically, both groups showed postoperative improvement as compared to their initial post-traumatic state. In group A, initially, the distribution of ASIA scale was seven patients with grade $A$, eight with grade $B$, five with grade $C$, and five with grade $\mathrm{D}$ but three with grade $\mathrm{A}$, four with grade $\mathrm{B}$, three with grade $\mathrm{C}$, nine with grade $\mathrm{D}$, and two with grade $\mathrm{E}$ at the time of last follow-up. In group B, initially, the distribution of ASIA scale was four with grade $\mathrm{A}$, five with grade $\mathrm{B}$, six with grade $C$, and eight with grade $D$, and but two with grade $\mathrm{A}$, four with grade $\mathrm{B}$, three with grade $\mathrm{C}, 10$ with grade $\mathrm{D}$, and four with grade $\mathrm{E}$ at the time of last follow-up. Surgical complications were found in five cases (two cases in group A and three cases in group B; 10.4\%) (Table 3).

Radiologic data of each group were shown in Tables 4 and 5. Group A had 24\% (6/25 cases) extraspinal injuries, such as rib fractures, hemothorax, radius fracture, humerus fracture, and intraabdominal bleeding. Extraspinal injuries of group B were $26 \%$ (6/23 cases) and each injury was similar in content (Tables 4 and 5). In both group, seven cases (14.6\%, 7/48 cases) were associ-

Table 3. Comparison of postoperative and clinical change between patients with continuous and noncontinuous multiple thoracolumbar vertebral fractures

\begin{tabular}{lcc}
\hline & Group A (contiguous type) & Group B (noncontiguous type) \\
\hline Kyphotic angle (T10-L2, mean) & & $25.5 \pm 13.0$ \\
Preoperative & $27.4 \pm 14.9$ & $23.5 \pm 15.0$ \\
Postoperative & $22.4 \pm 12.1$ & $11.8 \pm 10.5$ \\
Lordosis (T12-S1, mean) & $13.4 \pm 11.2$ & $30.1 \pm 9.5$ \\
Preoperative & $31.4 \pm 14.2$ & 7.5 \\
Postoperative & & 2.8 \\
VAS & 8.4 & 0.386 \\
Preoperative & 3.4 & 42.8 \\
Postoperative & & 33.4 \\
Korean ODI & 45.3 & 0.018 \\
Preoperative & 23.5 & \\
Postoperative & &
\end{tabular}

Initial neurologic status (ASIA)
$A: B: C: D: E$
$7: 8: 5: 5: 0$
$4: 5: 6: 8: 0$

Last F/U neurologic status

$A: B: C: D: E$

$3: 4: 3: 9: 2$

$2: 4: 3: 10: 4$

Surgical complication* (10.4\%)

2 3

*Instrument failure, epidural hematoma, and wound infection etc. VAS : visual analog scale, ODI : Oswestry disability index, ASIA : American Spinal Injury Association, F/U : follow up 
ated with cervical vertebral fractures (three cases : group A; four cases : group B) (Tables 4 and 5).

In group A (continuous fracture), there were 12 cases (48\%) in which minor fractures were not included into instrumentation, and 13 cases (52\%) in which minor fractures were included (Table 4).

In group B (noncontinuous fracture), there were 13 cases (56.5\%) which had one intervening normal vertebra, six cases $(26.1 \%)$ which had two intervening normal vertebrae, two cases $(8.7 \%)$ which had three intervening normal vertebrae, and two cases (8.7\%) which had four intervening normal vertebrae (Table 5). Six cases (26.1\%) did not included all intervening normal vertebrae and $19(82.6 \%)$ cases were instru- mented including all intervening normal vertebrae. Separate fusion was one case (Thoracic 8, Lumbar 1 fractures), in which T7-9, T12-L2 were both unstable burst fracture and fused for each of fracture because of avoiding long fusion.

Group A (continuous fracture) had 62 fractures and 84 vertebral segments fusions. In contrast, group B (noncontinuous fracture) had 54 fractures and 98 vertebral segments fusions.

\section{DISCUSSION}

Traumatic multiple spine injury with poly-trauma involves multiple injuries of varying severity ${ }^{5,6)}$. In addition to the spi-

Table 4. Radiologic data of multiple continuous thoracolumbar vertebral fractures

\begin{tabular}{|c|c|c|c|c|c|c|c|c|c|c|}
\hline & Age & Sex & Cause & Main Fx & Fx sites & $\begin{array}{c}\text { Fusion } \\
\text { range }\end{array}$ & N. of Fx & $\begin{array}{c}\text { N. of } \\
\text { fusion }\end{array}$ & Cervical Fx & Extraspinal injury \\
\hline 1 & 34 & $M$ & MVA & T8 & $\mathrm{T7}, \mathrm{T} 8$ & T7-9 & 2 & 3 & & Rib Fx, Radius Fx, SAH \\
\hline 2 & 36 & $\mathrm{~F}$ & MVA & $\mathrm{L} 2$ & $\mathrm{~L} 1, \mathrm{~L} 2$ & L1-3 & 2 & 3 & & \\
\hline 3 & 50 & M & Fall & $\mathrm{L} 2$ & $\mathrm{~L} 2, \mathrm{~L} 3$ & $\mathrm{~L} 2-4$ & 2 & 3 & C5 body & \\
\hline 4 & 45 & M & Fall & L1 & $\mathrm{T} 11, \mathrm{~T} 12, \mathrm{~L} 1$ & $\mathrm{~T} 12-\mathrm{L} 2$ & 3 & 3 & & Intraabdominal bleeding \\
\hline 5 & 34 & M & MVA & $\llcorner 4$ & $\mathrm{L} 3, \mathrm{~L} 4$ & L3-5 & 2 & 3 & & \\
\hline 6 & 55 & M & Other & $\mathrm{L} 2$ & $\mathrm{~T} 12, \mathrm{~L} 1, \mathrm{~L} 2$ & L1-3 & 3 & 3 & & Rib Fx, Sternum Fx \\
\hline 7 & 50 & F & Fall & $\mathrm{L} 1$ & $\mathrm{~T} 12, \mathrm{~L} 1$ & $\mathrm{~T} 12-\mathrm{L} 2$ & 2 & 3 & & \\
\hline 8 & 46 & $\mathrm{~F}$ & MVA & $\mathrm{L} 1$ & $\mathrm{~T} 12, \mathrm{~L} 1$ & $\mathrm{~T} 11-\mathrm{L} 2$ & 2 & 4 & & \\
\hline 9 & 43 & M & MVA & $\mathrm{T} 12$ & $\mathrm{~T} 11, \mathrm{~T} 12$ & T11-L1 & 2 & 3 & & \\
\hline 10 & 26 & $\mathrm{~F}$ & Fall & L1 & $\mathrm{T} 11, \mathrm{~T} 12, \mathrm{~L} 1$ & $\mathrm{~T} 12-\mathrm{L} 2$ & 3 & 3 & & \\
\hline 11 & 33 & M & MVA & $\mathrm{T7}$ & $\mathrm{T} 6, \mathrm{~T} 7$ & T5-T7 & 2 & 3 & C6 body & Rib Fx, Hemothorax \\
\hline 12 & 29 & $\mathrm{~F}$ & MVA & L1 & $\mathrm{T} 12, \mathrm{~L} 1$ & T11-L2 & 2 & 4 & & \\
\hline 13 & 41 & $\mathrm{~F}$ & Fall & $\mathrm{L} 1$ & $\mathrm{~T} 12, \mathrm{~L} 1$ & $\mathrm{~T} 11-\mathrm{L} 2$ & 2 & 4 & & \\
\hline 14 & 36 & M & MVA & $\mathrm{L} 1$ & $\mathrm{~T} 12, \mathrm{~L} 1$ & $\mathrm{~T} 11-\mathrm{L} 2$ & 2 & 4 & & \\
\hline 15 & 37 & $M$ & Fall & $\mathrm{T} 10$ & $\mathrm{~T} 10, \mathrm{~T} 11$ & T9-T11 & 2 & 3 & & \\
\hline 16 & 50 & $\mathrm{~F}$ & MVA & $\mathrm{L} 2$ & T11, T12, L1, L2 & L1-3 & 4 & 3 & & Femur neck Fx \\
\hline 17 & 20 & $M$ & MVA & L5 & $\llcorner 4,\llcorner 5$ & L3-IL & 2 & 5 & & \\
\hline 18 & 29 & $M$ & MVA & $\mathrm{T} 12$ & $\mathrm{~T} 12, \mathrm{~L} 1$ & T12-L2 & 2 & 3 & & Humerus Fx \\
\hline 19 & 32 & $M$ & Fall & L2 & $\mathrm{T} 11, \mathrm{~L} 2$ & T11-L3 & 2 & 3 & & \\
\hline 20 & 38 & M & Other & L1 & $\mathrm{T} 11, \mathrm{~T} 12, \mathrm{~L} 1$ & $\mathrm{~T} 11-\mathrm{L} 2$ & 3 & 4 & & \\
\hline 21 & 41 & M & MVA & $\mathrm{T} 12$ & $\mathrm{~T} 10, \mathrm{~T} 11, \mathrm{~T} 12, \mathrm{~L} 1$ & $\mathrm{~T} 12-\mathrm{L} 2$ & 4 & 3 & & \\
\hline 22 & 40 & M & MVA & $\llcorner 4$ & $L 2, L 3, L 4$ & L3-L5 & 3 & 3 & & \\
\hline 23 & 42 & $M$ & MVA & L2 & $\mathrm{T} 12, \mathrm{~L} 1, \mathrm{~L} 2$ & L1-L3 & 3 & 3 & & \\
\hline 24 & 32 & $M$ & Other & $\mathrm{T} 12$ & $\mathrm{~T} 10, \mathrm{~T} 11, \mathrm{~T} 12$ & $\mathrm{~T} 11-\mathrm{L} 2$ & 3 & 4 & C5 lamina & \\
\hline 25 & 33 & M & Other & $\mathrm{T} 12$ & $\mathrm{~T} 10, \mathrm{~T} 11, \mathrm{~T} 12$ & $\mathrm{~T} 11-\mathrm{L} 2$ & 3 & 4 & & \\
\hline
\end{tabular}

Fx: fracture, $M$ : male, MVA : motor vehicle accident, $\mathrm{SAH}$ : subarachnoid hemorrhage, $\mathrm{F}$ : female 
nal fracture and/or dislocation, there may be spinal cord injury with neurologic deficit, head injury, injuries to extremities, and injuries to thorax or intra-abdominal organ ${ }^{5,6)}$.

According to Heidari et al. ${ }^{6}$, $3.48 \%$ of total registered trauma patients had a traumatic spinal fracture to the spinal column and among spinal fracture patients, 27.6\% had associated non-spinal injuries. Of all patients with associated injuries, $74.3 \%$ had associated extremity injuries, and 32.2\% had head, thorax or abdomen injuries. The most common region of spinal fracture was the lumbar region (53.63\%), followed by the thoracic $(22.78 \%)$ and then the cervical $(19.22 \%)^{6)}$. In theirs study, of 619 cases of spine fractures, 27 patients (4.36\%) had multiple fractures of the spine, of which mainly were thoracic and lumbar spine fractures (25 cases) and then the cervical and lumbar spine fractures (two cases) ${ }^{6}$. Niedermeier and $\mathrm{Khan}^{19)}$ in 2017 presented that the multiple spine fracture occurred $4-8 \%$ in poly trauma patients.

In our study, 31.2\% (15 of 48 cases) had extra-spinal injuries, such as rib fractures, hemothorax, long bone fractures, intra-abdominal bleeding, intracranial lesion, etc. We observed $14.6 \%$ associated cervical fractures (seven of 48 cases) in multiple thoracolumbar fractures.

Calenoff et al. ${ }^{1)}$ in 1978 defined a noncontinuous multiple vertebral fracture to be a fracture of the vertebral body at two different levels with an interval of more than three normal vertebrae in between. However, Powell et al. ${ }^{20)}$ in 1989 suggested that the existence of even a single normal vertebral body between the fractured vertebrae could be considered as a

Table 5. Radiologic data of multiple noncontinuous thoracolumbar vertebral fractures

\begin{tabular}{|c|c|c|c|c|c|c|c|c|c|c|c|c|}
\hline & Age & Sex & Cause & Main Fx & Fx sites & $\begin{array}{c}\mathrm{N} . \text { of } \\
\text { intervening } \\
\text { normal } \\
\text { vertebra }\end{array}$ & Fusion range & N. of Fx & $\begin{array}{c}\text { N. of } \\
\text { Fusion }\end{array}$ & $\begin{array}{c}\text { N. of fused } \\
\text { intervening } \\
\text { normal } \\
\text { vertebra }\end{array}$ & $\begin{array}{c}\text { Cervical } \\
\text { Fx }\end{array}$ & $\begin{array}{l}\text { Extraspinal } \\
\text { injury }\end{array}$ \\
\hline 1 & 34 & M & MVA & $\mathrm{T} 12$ & $\mathrm{~T} 10, \mathrm{~T} 12$ & 1 & $\mathrm{~T} 10-\mathrm{L} 1$ & 2 & 4 & 1 & & \\
\hline 2 & 36 & $\mathrm{~F}$ & MVA & L3 & L1, L3 & 1 & L1-L4 & 2 & 4 & 1 & & Rib Fx \\
\hline 3 & 50 & M & MVA & L4 & $\mathrm{L} 2, \mathrm{~L} 4$ & 2 & L1-L5 & 2 & 5 & 2 & & \\
\hline 4 & 45 & M & Fall & L1 & $\mathrm{T} 11, \mathrm{~T} 12, \mathrm{~L} 2$ & 1 & T11-L2 & 3 & 4 & 1 & & \\
\hline 5 & 34 & M & MVA & L5 & $\mathrm{L} 3, \mathrm{~L} 5$ & 1 & L3-IL & 2 & 5 & 1 & & \\
\hline 6 & 55 & M & Fall & $\mathrm{T} 11$ & $\mathrm{~T} 6, \mathrm{~T} 11, \mathrm{~T} 12$ & 2 & T10-L1 & 3 & 4 & 1 & & \\
\hline 7 & 50 & F & Fall & L2 & $\mathrm{T} 10, \mathrm{~L} 2$ & 3 & T12-L3 & 2 & 4 & 1 & & Tibia Fx \\
\hline 8 & 46 & F & MVA & L2 & $\mathrm{T} 12, \mathrm{~L} 2$ & 1 & T12-L3 & 2 & 4 & 1 & & \\
\hline 9 & 32 & M & Other & $\mathrm{L} 2$ & $\mathrm{~T} 11, \mathrm{~L} 2$ & 2 & T10-L3 & 2 & 5 & 2 & & \\
\hline 10 & 26 & $\mathrm{~F}$ & MVA & L1 & $\mathrm{T} 10, \mathrm{~T} 12, \mathrm{~L} 1$ & 1 & T11-L3 & 3 & 5 & 1 & & Rib Fx \\
\hline 11 & 33 & M & Fall & $\mathrm{T} 12$ & $\mathrm{~T} 10, \mathrm{~T} 12$ & 1 & T10-L2 & 2 & 4 & 1 & & \\
\hline 12 & 29 & $\mathrm{~F}$ & MVA & $\mathrm{L} 1$ & T8, L1 & 4 & T12-L3 & 2 & 4 & 1 & C5,6 body & Rib Fx \\
\hline 13 & 41 & $F$ & MVA & $\llcorner 4$ & $\mathrm{T} 12, \mathrm{~L} 4$ & 3 & L3-S1 & 2 & 4 & 1 & & \\
\hline 14 & 36 & $\mathrm{~F}$ & MVA & $\mathrm{T} 12$ & $\mathrm{~T} 12, \mathrm{~L} 3$ & 2 & $\mathrm{~T} 11-\mathrm{L} 3$ & 2 & 5 & 2 & & \\
\hline 15 & 37 & M & MVA & $\mathrm{T} 12$ & $\mathrm{~T} 10, \mathrm{~T} 12$ & 1 & $\mathrm{~T} 10-\mathrm{L} 2$ & 2 & 5 & 1 & C4,5 body & \\
\hline 16 & 50 & M & MVA & L3 & T11, T12, L3 & 2 & $\mathrm{~L} 2-\mathrm{L} 5$ & 3 & 5 & 2 & & \\
\hline 17 & 46 & M & Fall & L5 & $\mathrm{L} 2, \mathrm{~L} 5$ & 2 & $\llcorner 4-S 1$ & 2 & 3 & 2 & & Radius Fx \\
\hline 18 & 29 & M & MVA & $\mathrm{L} 2$ & $\mathrm{~T} 12, \mathrm{~L} 2$ & 1 & L1-Ł4 & 2 & 4 & 1 & & \\
\hline 19 & 39 & M & MVA & $\mathrm{L} 1$ & T8, L1 & 4 & $\mathrm{~T} 7-9, \mathrm{~T} 12-\mathrm{L} 2^{*}$ & 2 & 3 & 2 & C5 lamina & \\
\hline 20 & 38 & M & MVA & T8 & T6, T8, T9 & 1 & T7-T10 & 3 & 4 & 1 & & \\
\hline 21 & 41 & M & Fall & $\mathrm{T} 12$ & $\mathrm{~T} 10, \mathrm{~T} 12, \mathrm{~L} 1$ & 1 & T11-L3 & 3 & 5 & 1 & & Hemothorax \\
\hline 22 & 44 & M & Other & L2 & T10, T12, L1, L2 & 1 & $\mathrm{~T} 12-\mathrm{L} 4$ & 4 & 5 & 0 & C6 spinous & Skull Fx \\
\hline 23 & 36 & M & Other & $\mathrm{T} 12$ & $\mathrm{~T} 10, \mathrm{~T} 12$ & 1 & T10-L1 & 2 & 3 & 1 & & \\
\hline
\end{tabular}

*Separate fusion. Fx : fracture, $M$ : male, MVA : motor vehicle accident, F : female 
noncontinuous multiple vertebral fracture. The incidence of noncontinuous multiple vertebral fractures has been reported to range from $1.6 \%$ to $16.7 \% \%^{7,823)}$.

Regarding the pathogenesis of noncontinuous fracture, some authors have claimed that a concentration of force might result in a severe vertebral fracture in one area and secondary, less severe fracture(s) in another area due to the action of secondary force ${ }^{7,22)}$. Therefore, it was presumed that relatively stable fracture(s) occur in the other vertebrae because the force is dispersed to various spine regions ${ }^{7}$. Some authors have reported that noncontinuous multiple vertebral fractures are mostly caused by external forces and tend to have osteoporosis as a contributing factor, while continuous multiple vertebral fractures have been reported to be caused by high-energy trauma ${ }^{3,9}$.

Dai and $\mathrm{Jia}^{3)}$ in 1996 suggested that continuous multiple vertebral fractures have a complex mechanism and show more severe injury and prognosis than does a solitary vertebral fracture and that a severe external force is concentrated on one vertebra, causing a severe fracture (i.e., a fracture that is directly related to instability or neurological signs) and a second fracture on the successive vertebra (i.e., a secondary fracture that might contribute to symptoms or neurological signs). However, in more recent years, it has been indicated that both main and minor fractures are relatively stable as a result of the dispersion of forces due to the multiple fracture ${ }^{15)}$. But, there has been no consensus on the pathogenesis of noncontinuous vertebral fractures.

In this study, we classified a noncontinuous fracture case as when more than one nonfractured vertebral body was present between separated fractures; considering this criterion, 13 cases had one non-injured vertebra, six cases had two, two cases had three, and two cases had four, respectively (Table 5, Fig. 1). About the fusion range of noncontinuous fracture group, $82.6 \%$ (19/23 cases) were cases, in which all vertebral fractures including intervening normal vertebrae were instrumented.

In 2007, Lian et al. ${ }^{15)}$ claimed that the treatment of multilevel noncontiguous spinal fractures requires particular attention and must be individualized and certain factors must be taken into account, such as neurological deficit, spine instability and deformity, and the number of intact spinal units between the two fractures. They also proclaimed that if one lesion is stable without neurological deficit, and the second is unstable or attributing to neurologic deficit, only the second site was treated surgically and the other conservatively. In the patients that had a spinal cord injury corresponding to the upper level fracture, the lower level was treated non-operatively only if it was
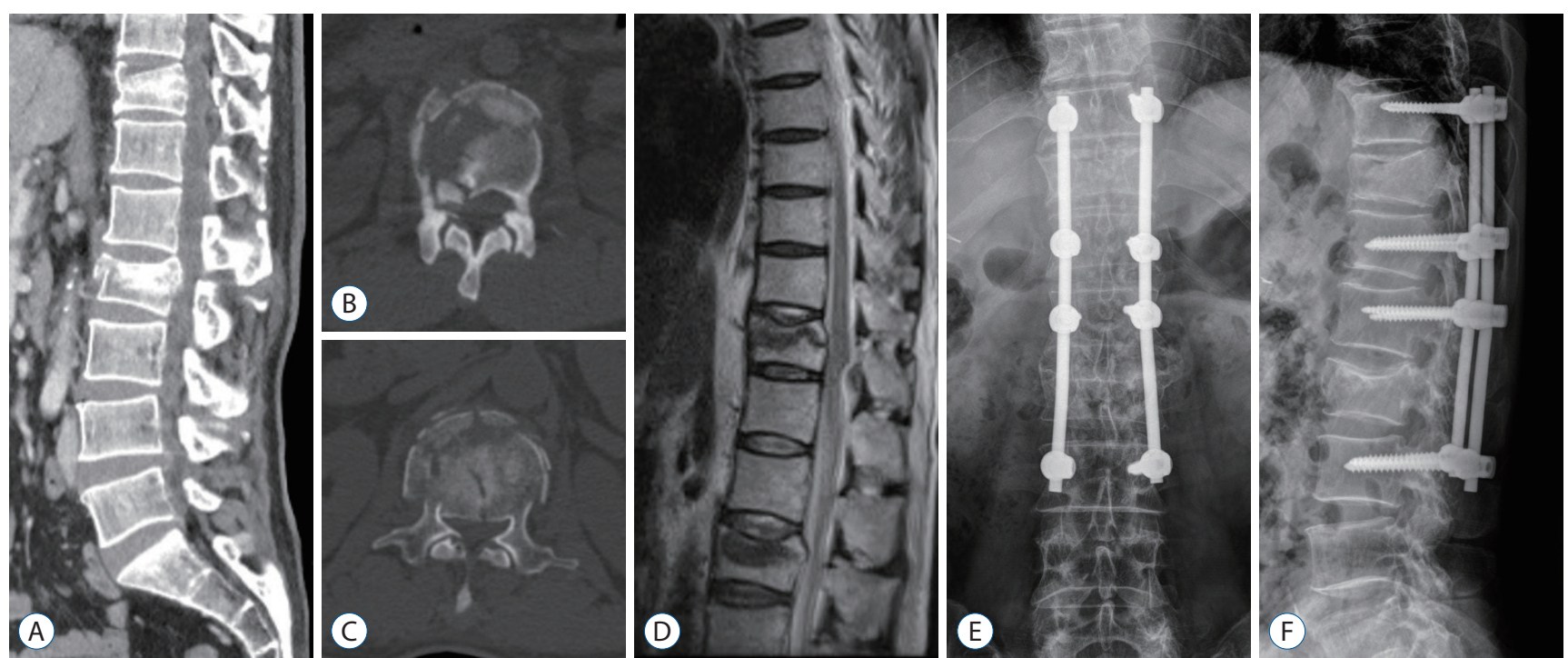

Fig. 1. A 32-year-old man with noncontinous thoracolumbar fractures. He fell from the second floor and the physical exam at the emergency department showed motor grade II below the $\mathrm{L} 2$ level and a tingling sensation in both lower limbs. A-C: A lumbar CT shows fractures on the T11 and L2 vertebral bodies. Axial CT scan shows severe canal compromise at both T11 and L2. D: MR sagittal scan demonstrates spinal canal compromise. E and F : Instrumentation and posterolateral fusion of T10- $\mathrm{L} 3$ with posterior decompression of $\mathrm{L} 2$ was performed. $T 11$ fracture had spinous process fracture and then we included $\mathrm{T} 11$ into instrumented level. CT: computed tomography, MR: magnetic resonance. 
stable and no compression of spinal cord was shown in MRI or CT.

Multiple vertebral fractures are most often caused by highenergy injuries including complicated traffic accidents or falls from large heights ${ }^{22)}$. Henderson et al. ${ }^{7)}$ in 1991 and Korres et al. ${ }^{13)}$ in 2003 also reported that traffic accidents were the most common cause of multiple vertebral fractures. In the present study, traffic accidents were the most common cause of multiple vertebral fractures. Separately, in the case of a fall, the most frequent occurrence was a fall from the height of two stories. It is thought that a fall from a large height would prevent the patient from receiving a spinal operation due to multiple organ injuries ${ }^{5,6)}$.

The thoracolumbar spine was the most common site of fracture according to the injury mechanism ${ }^{19}$. In the present study, 31 (64.6\%) of the 48 cases were located in the thoracolumbar junction. The thoracolumbar junction (T11-L2) site, which is a biomechanically transitional zone from the stable thoracic spine to the flexible lumbar spine, is known to have a high probability of injury ${ }^{9,19)}$.

Since the advent of MRI and CT scans, the delayed diagnosis of secondary fractures has been reduced. However, in a multiple vertebral fracture scenario, a fracture related to a neurological symptom or spinal deformity is easily diagnosed, but a fracture site where a neurological symptom is imposed or less severe may be overlooked and sometimes the diagnosis of other vertebral fractures is delayed ${ }^{14)}$. In patients with noncontinuous multiple vertebrae fractures, the primary fracture site is easily diagnosed clinically and radiologically, but the diagnosis of secondary fractures often tends to be delayed. According to some reports, it took 2.8 to 52.6 days to diagnose the secondary fracture site ${ }^{8,13)}$. The reasons for the delayed diagnosis of other vertebral fractures are as follows ${ }^{13,20)}$. First, there are many cases where radiological fractures are not observable in plain X-rays. Second, radiologic studies of the upper-level spine are not as commonly performed. Third, there may be a lack of clinical experience among the involved health care professionals. Therefore, while it is not immediately necessary, if a fracture is diagnosed at one region of the spine, radiologic studies for other regions should subsequently be completed. A full sagittal MRI scan and radioisotopic bone scan may be helpful to prevent delayed diagnosis in cases of multiple trauma and complicated injury ${ }^{10)}$.

There were no demographical or initial clinical differences relating to sex ratio, age distribution, cause of injury, or initial neurologic status (ASIA score) between the two groups. Radiologically, the number of fractures, kyphotic angle, and lordosis angle were not different between groups. However, the
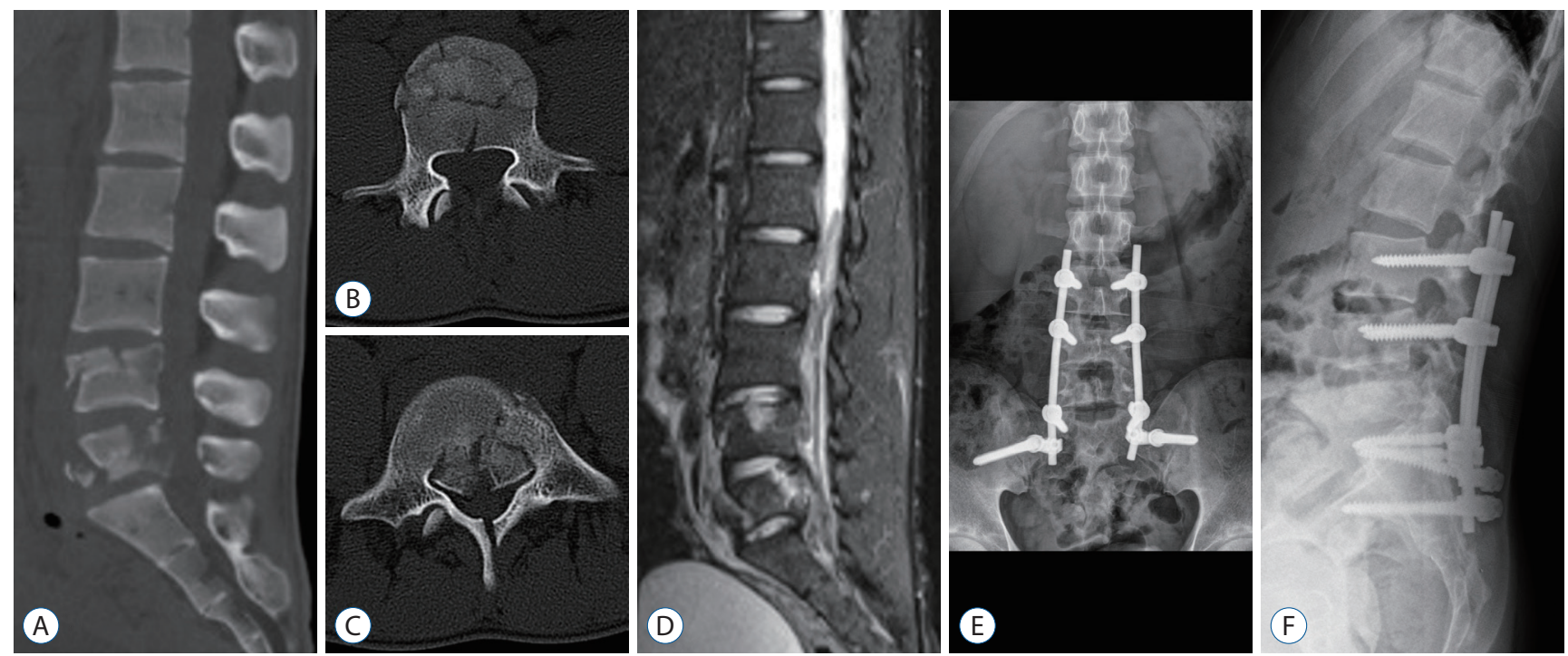

Fig. 2. A 20-year-old man with continous thoracolumbar fractures. He injured from traffic accident. The physical exam at the emergency department showed motor grade III below the L4 level and a tingling sensation in both lower limbs. A-C : A lumbar CT and MRI show stable burst fracture and unstable burst fractures on the L4, L5 on each other. Axial CT scan shows severe canal compromise at L5. D : MR sagittal T2 scan demonstrates cauda equina compression and instability. $\mathrm{E}$ and $\mathrm{F}$ : Instrumentation from $\mathrm{L} 3$ to pelvis and posterolateral fusion with posterior decompression of $\mathrm{L} 5$ was performed. We could reduce instrumentation level by inserting screws into L4 fractured vertebral body. CT : computed tomography, MR: magnetic resonance, MRI : magnetic resonance imaging. 
number of instrumented vertebral segments in group B (noncontinuous fractures) was higher than that in group A. Here, it is presumed that there existed nonfractured segments inbetween and these segments were included to be fixed. Patients with noncontinuous fractures often require long segment instrumentation so as to include all fractures in order to obtain firm stabilization.

In this study, burst type fractures were overwhelmingly the most common, followed by distraction injury, translation injury, and chance fracture, respectively, in both groups (Fig. 2). The distribution of fracture type was similar. As such, the mechanism of multiple fractures is presumed to be the same between continuous and noncontinuous fractures.

Powell et al. ${ }^{20)}$ reported that surgical treatment is mandatory for all fractured vertebral segments in noncontinuous multiple vertebral fractures. Conversely, though, Lian et al. ${ }^{15)}$ in 2007 emphasized that one fracture does not affect the other fracture site and that the extent of instrumentation should be selected according to the degree of spinal instability, type of fracture, and level of vertebral deformity. Although long-segment fixation can maintain firm stability in the immediate postoperative period, such may cause degenerative changes in the adjacent segments and decrease the vertebral motion due to a reduction in the motion segment. This could eventually cause discomfort in the activities of daily life due to limitations of motion after long fusion ${ }^{21)}$.

In this study, both groups A and B had similar clinical and radiologic features, although group A was comprised of neurologically slightly worse patients than group B based on ASIA scores, group A ultimately also had better clinical outcomes in terms of activities of daily life in long-term follow-up KODI scores. The number of instrumented segments in group A was less than that in group B and the clinical features in group A improved more during the long-term period. But, some authors suggested that long-term clinical result affected from not only surgical fusion option but also initial neurologic injury, kyphotic deformity, combined extraspinal injury, neuropathic pain ${ }^{3,7,9)}$.

Therefore, considering the relatively young age and the quality of life after surgery of patients with multiple vertebral fractures, it is advisable to perform short-segment fixation rather than long-segment fixation ${ }^{18)}$.

Meanwhile, spine surgeons have been trying to reduce fixed segments ${ }^{18)}$. As part of this, if a vertebral body fracture but in- tact pedicle is well-established, then short-segment fixation rather than long-segment fixation is preferable because additional fixation can be obtained through insertion into intact pedicles in spite of the existence of the vertebral body fracture ${ }^{4}$. According to Chen et al. ${ }^{2)}$, Guven et al. ${ }^{4)}$, and Liu et al. ${ }^{16)}$, through research of the changes in vertebral height and sagittal index, there was no difference noted in the fixation strength between short-segment fixation, including screw fixation into the fractured vertebral body via intact pedicle, and long-segment fixation. The incidence of complications including pulmonary embolism, instrument failure, respiratory distress syndrome, postoperative delirium, epidural hematoma, infection, and neurological injury tends to increase in long-segment fixation than short-segment fixation. Thus, it is advisable that surgeon efforts be focused on reducing the length of segment fixa$\operatorname{tion}^{16,21)}$.

However, if decompressive laminectomy or a highly unstable or severely deformed spine is suspected, it is necessary to consider using long-segment fixation depending on the characteristics of each fracture, the stability of the spine, and to identify the proper fixation range rather than simply adopting a typical short-segment fixation approach ${ }^{16,21)}$.

In our study, surgical complications including instrument failure, epidural hematoma, and wound infection were relatively similar among both groups.

The main disadvantage of this study is the retrospective study. A limitation of this study include that most of the fractures due to trauma occurred at relatively young ages and bone density was not measured in all patients, so the possibility of osteoporotic vertebral fracture was not accurately excluded. Due to various fracture morphologies, kyphosis, neurologic status and surgical option, it was difficult to conclude preliminary assumption that continuous fracture group had better clinical outcomes in terms of activities of daily life in long-term follow-up.

The number of cases was small and the follow-up periods were relatively short to successfully obtain statistically significant conclusions. It is expected that more patients will be studied in the future and more meaningful results will be obtained if additional studies are conducted on the results of radiological evaluation as well as clinical evaluation. 


\section{CONCLUSION}

There were no significant differences in demographic findings, the type of fracture, the number of fractures, kyphosis, lordosis, or complications between the continuous and noncontinuous vertebral fracture groups, but the numbers of instrumented segments and long-term clinical functional assessment showed better results in the continuous group. Considering the relatively young age and the quality of life after surgery of patients in multiple vertebral fractures, it is advisable to perform short-segment fixation rather than longsegment fixation whenever possible.

\section{CONFLICTS OF INTEREST}

No potential conflict of interest relevant to this article was reported.

\section{INFORMED CONSENT}

Informed consent was obtained from all individual participants included in this study.

\section{AUTHOR CONTRIBUTIONS}

\author{
Conceptualization : YC \\ Data curation : YC, YGK \\ Formal analysis : YC, YGK \\ Methodology : YC, YGK \\ Project administration : YC \\ Visualization : YC, YGK \\ Writing - original draft : YC, YGK \\ Writing - review \& editing : YC, YGK
}

\section{References}

1. Calenoff L, Chessare JW, Rogers LF, Toerge J, Rosen JS : Multiple level spinal injuries: importance of early recognition. AJR Am J Roentgenol $130: 665-669,1978$

2. Chen F, Kang Y, Li H, Lv G, Lu C, Li J, et al. : Treatment of lumbar split fracture-dislocation with short-segment or long-segment posterior fixa- tion and anterior fusion. Clin Spine Surg 30 : E310-E316, 2017

3. Dai LY, Jia LS : Multiple non-contiguous injuries of the spine. Injury 27 : 573-575, 1996

4. Guven O, Kocaoglu B, Bezer M, Aydin N, Nalbantoglu U : The use of screw at the fracture level in the treatment of thoracolumbar burst fractures. J Spinal Disord Tech 22 : 417-421, 2009

5. Hebert JS, Burnham RS : The effect of polytrauma in persons with traumatic spine injury. A prospective database of spine fractures. Spine (Phila Pa 1976) 25 : 55-60, 2000

6. Heidari P, Zarei MR, Rasouli MR, Vaccaro AR, Rahimi-Movaghar V : Spinal fractures resulting from traumatic injuries. Chin J Traumatol 13 : 3-9, 2010

7. Henderson RL, Reid DC, Saboe LA : Multiple noncontiguous spine fractures. Spine (Phila Pa 1976) 16 : 128-131, 1991

8. Jo DJ, Kim SM, Kim KT, Seo EM : Surgical experience of neglected lower cervical spine fracture in patient with ankylosing spondylitis. J Korean Neurosurg Soc 48 : 66-69, 2010

9. Kano S, Tanikawa H, Mogami Y, Shibata S, Takanashi S, Oji Y, et al. : Comparison between continuous and discontinuous multiple vertebral compression fractures. Eur Spine J 21 : 1867-1872, 2012

10. Kerttula LI, Serlo WS, Tervonen OA, Pääkkö EL, Vanharanta HV : Posttraumatic findings of the spine after earlier vertebral fracture in young patients: clinical and MRI study. Spine (Phila Pa 1976) 25 : 11041108,2000

11. Kim DY, Lee SH, Lee HY, Lee HJ, Chang SB, Chung SK, et al. : Validation of the Korean version of the oswestry disability index. Spine (Phila Pa 1976) 30 : E123-E127, 2005

12. Knop C, Oeser M, Bastian L, Lange U, Zdichavsky M, Blauth M : Development and validation of the visual analogue scale (VAS) spine score. Unfallchirurg 104 : 488-497, 2001

13. Korres DS, Boscainos PJ, Papagelopoulos PJ, Psycharis I, Goudelis G, Nikolopoulos K : Multiple level noncontiguous fractures of the spine. Clin Orthop Relat Res : 95-102, 2003.

14. Korres DS, Katsaros A, Pantazopoulos T, Hartofilakidis-Garofalidis G : Double or multiple level fractures of the spine. Injury $13: 147-152$, 1981

15. Lian XF, Zhao J, Hou TS, Yuan JD, Jin GY, Li ZH : The treatment for multilevel noncontiguous spinal fractures. Int Orthop 31 : 647-652, 2007

16. Liu Z, Zhang P, Zeng $H, X u Z$, Wang X : A comparative study of singlestage transpedicular debridement, fusion, and posterior long-segment versus short-segment fixation for the treatment of thoracolumbar spinal tuberculosis in adults: minimum five year follow-up outcomes. Int Orthop 42 : 1883-1890, 2018

17. McAfee PC, Yuan HA, Fredrickson BE, Lubicky JP : The value of computed tomography in thoracolumbar fractures. An analysis of one hundred consecutive cases and a new classification. J Bone Joint Surg Am 65 : 461-473, 1983

18. McLain RF : The biomechanics of long versus short fixation for thoracolumbar spine fractures. Spine (Phila Pa 1976) 31 : S70-S79; discussion S104, 2006

19. Niedermeier SR, Khan SN : Polytrauma patients with associated spine 
fractures: an assessment of surgical intervention on patient outcome. Clin Spine Surg 30 : E38-E43, 2017

20. Powell JN, Waddell JP, Tucker WS, Transfeldt EE : Multiple-level noncontiguous spinal fractures. J Trauma 29 : 1146-1150; discussion 11501151, 1989

21. Ruan DK : Fixation for the thoracolumbar spine fracture: long-segment versus short-segment. Zhongguo Gu Shang 22 : 483-484, 2009

22. Seçer $M$, Alagöz F, Uçkun O, Karakoyun OD, Ulutas MÖ, Polat Ö, et al. : Multilevel noncontiguous spinal fractures: surgical approach towards clinical characteristics. Asian Spine J 9 : 889-894, 2015

23. Wittenberg RH, Hargus S, Steffen R, Muhr G, Bötel U : Noncontiguous unstable spine fractures. Spine (Phila Pa 1976) 27 : 254-257, 2002 